\title{
Hong Kong Output Dynamics: An Empirical Analysis
}

\author{
Yin-Wong Cheung \\ University of California, Santa Cruz \\ Hong Kong Institute for Monetary Research
}

December 2000

\begin{abstract}
Advanced statistical techniques are used to analyze Hong Kong output dynamics. Hong Kong, Japan and the U.S. are found to share some common long-term and short-term cyclical variations. While the Hong Kong economy is susceptible to external shocks and is "Granger-caused" by the other two economies, local factors account for a large proportion of output growth variability and are mainly responsible for output uncertainty. On the transmission mechanism, the selected trade and financial variables have incremental explanatory power but do not lessen the ability of domestic and foreign output variables to explain Hong Kong growth dynamics. Interestingly, the U.S. does not appear to exert undue influence on Hong Kong.
\end{abstract}

JEL: E32, F42, C22

Keywords: Common Trends/Cycles, Transmission Mechanism, Structural Determinants

The author is grateful to Kenneth Chan, Steve Ching, Michael Devereux, Chander Kant, Simon Kwan, Guy Meredith, and Matthew Yiu for their helpful comments and suggestions. This paper was completed when the author was a research fellow at the Hong Kong Institute for Monetary Research, and he thanks the Institute for its hospitality. Desmond Hou provided excellent research assistance. The views expressed in this paper are those of the author and do not necessarily reflect those of the Hong Kong Institute for Monetary Research, its Council of Advisers, or Board of Directors. 


\section{Introduction}

Critics usually assert that exchange rate fixity impairs economic performance as it limits an economy's ability to respond and adjust to external shocks. Since October 1983, Hong Kong has adopted the linked exchange rate system - a de facto currency board that effectively pegs the Hong Kong dollar to the U.S. dollar at the rate of 7.8. The linked exchange rate arrangement does not provide much room for discretionary monetary policy to offset external shocks. The policy inflexibility imposed by the exchange rate link can be critical for Hong Kong, which is a small open economy susceptible to strong foreign influences.

However, there is no simple answer to the question of the economic consequences of adopting a specific exchange rate policy. The theoretical implications of exchange rate choice for economic performance depend on, for example, the relative magnitudes of demand and supply shocks and of domestic and foreign shocks (Marston, 1985). The shock transmission mechanism under a specific exchange rate arrangement depends on institutional factors such as wage and price setting rules (Dornbusch, 1983; Devereux and Engel, 1998). The importance of policy credibility in assessing the economic implications of exchange rate regimes is pointed out by, for example, Flood and Hodrick (1986). Melvin (1985) and Berger et al. (2000), on the other hand, argue that the exchange rate regime is chosen endogenously, and output variances in the home and foreign countries are robust predictors of the exchange rate regime choice.

The extant empirical studies do not offer unambiguous evidence on the effect of exchange rate choice on economic performance. For instance, Frankel and Mussa (1980) and Flood and Rose (1995) argue that fixing exchange rates will increase the volatility of economic fundamentals. Baxter and Stockman (1989), on the other hand, claim that there is little evidence of systematic differences in the behavior of macroeconomic aggregates under alternative exchange rate regimes. On shock transmissions, Lastrapes and Koray (1990) find that, under either a fixed or flexible rate regime, the degree of insulation and interdependence has a large variation across similar European countries. Using data from different sample periods, Hutchison and Walsh (1992) and Kim (2000) report that exchange rate flexibility is more effective in insulating the $\mathrm{J}$ apanese economy from foreign shocks.

In general, one has to exercise caution when interpreting the observed differences in economic performance under alternative exchange rate regimes. Exchange rate policy is the cause if the nature of shocks to economies under different exchange rate regimes are the same and the change in exchange rate policy is the only fundamental event. These two conditions are rarely met in reality. Thus, the real challenge is to discern the effect of exchange rate choice among forces impacting the economic performance.

In this exercise, we analyze the Hong Kong output dynamics. As it is impossible to isolate the exchange rate regime effect from other economic and non-economic factors before and after October 1983, we focus on the output dynamics during the current linked exchange rate system. ${ }^{1}$ While no explicit effort

1 Hong Kong adopted a sterling-based currency board from 1935 to 1972. See J ao (1998) for a detailed description of the sterling-based currency board and the current dollar-based currency board. 
is made to assess the output implication of the linked exchange rate system, the empirical results shed some light on the influences of the U.S., whose currency is the anchor currency of the linked exchange rate system, on the Hong Kong economy. Thus, the exercise offers some indirect evidence on the output implication of the exchange rate arrangement.

First, we examine the output relationships between Hong Kong, the U.S., and J apan. ${ }^{2}$ Given its substantial size and prominent status on the international stage, the U.S. is widely conceived to be the locomotive for the world economy and have significant impacts on others. Also, the U.S. dollar is the anchor currency of Hong Kong's linked exchange rate system. Even though the J apanese economy has experienced some difficulties in the past decade, it still plays an active role on the world economic stage and has significant economic interests in Far East economies. ${ }^{3}$ Moreover, both U.S. and J apan are major trading partners of Hong Kong. ${ }^{4}$

We conduct a systematic analysis of Hong Kong's long-run and short-run dependencies on developments in the U.S. and J apan. The cointegration approach and the vector error correction model are used to investigate the long-run and short-run interactions between aggregate output data. Conditioning on cointegration results, we assess the causal relationship among the output series. In addition, we employ the impulse response and forecast error variance decomposition techniques to evaluate the contributions of external factors to Hong Kong output dynamics.

The study of long-run and short-run interactions between national output data bears significant implications for economic growth theories. For instance, the real business cycle and endogenous growth models (Kydland and Prescott, 1982; Romer, 1986) offer different implications on the convergence of aggregate output data. These theories also have different prescriptions for growth policies. Recent empirical studies on discriminating between various convergence patterns include Cheung and Westermann (1999a) and Lee (1998). Durlauf and Quah (1999) contain an extensive review on the literature. In contrast to most of the existing studies, which focus on developed countries, the current exercise provides evidence on the output interactions between a newly developed economy (Hong Kong) and two developed countries.

In policy circles, large output fluctuations are usually considered unappealing. To devise an effective policy to reduce output variability, it is important for a small open economy like Hong Kong to gauge the relative importance of domestic and foreign shocks. If foreign shocks are largely responsible for output fluctuations, then authorities should direct policies toward insulating the economy from external factors. On the other hand, if domestic shocks are the main source of output fluctuations, then a reasonable policy is to establish a more stable and predictable economic environment.

2 Cheung et al. (1994), for example, show that U.S. and J apan factors can explain a large proportion of equity return variability in several Pacific Basin stock markets including Hong Kong.

3 Using the path analysis, Kwan et al. (1999) show that J apan has significant impacts on Asian countries including Hong Kong.

4 Due to the paucity of quality data, Mainland China - another major trading partner of Hong Kong - is considered only in the second part of the exercise. 
It is widely perceived that the existence of common business cycles has important policy implications. For instance, the choice of optimal currency regime and the need for monetary integration depend crucially on business cycle comovements (Mundell 1961). Furthermore, the effectiveness of trade policies depends on whether there is a strong cyclical comovement across countries. A high correlation might render, for example, real exchange rate policies targeting the trade sector ineffective in the short run. The empirical evidence on the existence of common business cycles is mixed. For instance, Campbell and Mankiw (1989) and Cheung (1994) report the absence of common cycles in the G7 countries. However, using different techniques, Canova and Marrinan (1998), Lumsdaine and Prasad (1997), and Cheung and Westermann (1999a) report stronger evidence on the presence of common business cycles. In this exercise, a recently proposed time-series econometric technique, namely the common feature test, is used to determine if Hong Kong, U.S., and J apan share some common business cycles.

A related issue is the influence of large economies on smaller ones. In Europe, there is an active debate on the dominating economic status of Germany. For instance, some perceive the German effect to be so great that Austrian policies are mainly geared towards the German market (Cheung and Westermann, 1999b, 2000). Another example is the U.S. influence on the Canadian economy. The current study will provide additional data on the possible effects of large economies on a small open economy.

In addition to the relative importance of domestic and foreign shocks, it is crucial to determine the channels through which the shocks are transmitted. Different transmission mechanisms may require different policies to alleviate unfavorable foreign shocks. There are a number of studies on transmission channels. Though it is generally believed that shocks are transmitted across economies via trade and financial linkages, the extant studies are mainly focused on the goods market effect. Canova and Dellas (1993), for instance, show that transmission of country-specific shocks depends on trade linkages in intermediate goods. More recently, Canova and Marrinan (1998) illustrate that the nature of the shocks affecting the economy plays a role in determining the ability of production and consumption interdependencies to explain transmission patterns. The goods market is also seen as the main channel for international risk sharing (Cole and Obstfeld, 1991).

To identify the possible transmission channels, the second part of the empirical analysis evaluates the effects of trade and financial variables on Hong Kong output dynamics. The time series model specification considered in the first part is extended to appraise Hong Kong output dynamics. The extended model evaluates the roles of trade flows and financial variables in the shock transmission mechanism and identifies the channels through which foreign shocks affect Hong Kong. If, for example, the U.S. output shock affects Hong Kong mainly through the trade channel, then a possible strategy to alleviate the impact of U.S. shocks is to diversify trade and establish a more substantial trading relationship with other countries. On the other hand, if the trade account is not the main channel through which foreign shocks affect Hong Kong, then we have to consider alternative policies to mitigate external shocks.

In the next section, we present the preliminary data analysis. Section 3 reports the cointegration and common feature test results. There is evidence that the output data from the three economies tend to move together in the long run and share some common business cycles. The effects of trade and financial variables on Hong Kong output dynamics are examined in Section 4. Section 5 contains some concluding remarks. 


\section{Preliminary Analysis}

The quarterly output data of Hong Kong, U.S., and J apan from 1984:I to 1999:Il are considered. Data on real gross domestic product and population were taken from the International Financial Statistics and CEIC databases to construct the per capita real output (henceforth, output for short). The U.S. and J apan data are seasonally adjusted at the source. The Hong Kong data are seasonally adjusted using regression dummies. All the output data are expressed in logs. ${ }^{5}$

The ADF-GLS test that is a modified augmented Dickey-Fuller test proposed by Elliott et al. (1996) is used to test for the presence of a unit-root in the output series. The modified test is shown to have better power than the usual ADF procedure. The ADF-GLS test that allows for a linear time trend is based on the regression

$$
\Delta Y_{i t}^{\tau}=\phi_{0} Y_{i t-1}^{\tau}+\sum_{j=1}^{p} \phi_{j} \Delta Y_{i t-j}^{\tau}+\varepsilon_{i t},
$$

where $\Delta$ is the lag operator, $\varepsilon_{i t}$ is the error term, and $Y_{i t}^{\tau}$ is the economy $i$ 's locally detrended output series at time $t$ for $i=$ Hong Kong, the U.S., and J apan. The locally detrended variable $Y_{i t}^{\tau}$ is given by $Y_{i t}^{\tau}=Y_{i t}-Z_{t} \gamma$, with $\gamma$ being the least squares regression coefficient of $\tilde{Y}_{i}$ on $\tilde{Z}$, for which $\tilde{Y}_{i}=\left(Y_{i 1},(1-\bar{\rho} \Delta)\right.$ $\left.Y_{i 2}, \ldots,(1-\bar{\rho} \Delta) Y_{i T}\right)^{\prime}, \tilde{Z}=\left(Z_{1},(1-\bar{\rho} \Delta) Z_{2}, \ldots,(1-\bar{\rho} \Delta) Z_{T}\right)^{\prime}, Z_{t}=(1, t)$ and $Y_{i t}$ is economy $i$ 's output at time $t$. Following Elliot et al. (1996) the local parameter $\bar{\rho}=\bar{c} / T$ is defined by setting $\bar{c}=-13.5$. Under the unitroot null hypothesis, $\phi_{0}=0$. The test results are given in Table 1 . The lag parameter is chosen by the Akaike information criterion (AIC). The portmanteau Q-test statistic indicates that the three selected models adequately described the dynamics in the output data. For each series, the unit-root hypothesis is not rejected - suggesting that there is at least one unit root in the data.

To ensure that there is no more than one unit root in each output series, the ADF-GLS test allowing for an intercept but not a time trend is applied to the first-differenced data. The procedure is similar to the one described above except (a) the locally detrended variable $Y_{i t}^{\tau}$ is replaced by $Y_{i t}^{\mu}$, a locally demeaned variable constructed with $Z_{t}=(1)$ instead of $Z_{t}=(1, t)$, and $(b) \bar{c}$ is set equal to -7 . In this case, the unit-root hypothesis is rejected (Table 1.B). As the unit-root hypothesis is rejected by the first-differenced data but not by the data themselves, we infer that the output data series have only one unit root.

The unit root test result is consistent with both real business cycle and endogenous growth models. In a canonical real business cycle model, the stochastic output trend is driven by exogenous technological progresses. For an endogenous growth model, endogenous growth generating mechanisms can induce I(1) nonstationarity to output data even in the absence of exogenous growth generating factors (Lau, 1999). In the subsequent analysis, we assume each output data series is difference-stationary.

The first-differenced output data are depicted in Figure 1 and their variances and correlation coefficients are given in Table 1.C. Among the three economies, Hong Kong has the highest output growth variability. The high output variation in the beginning of the sample period came after the 1982-83 financial crisis,

5 The output data and the data used in the following sections are available from the Hong Kong Institute for Monetary Research. 
which led to the establishment of the existing currency board system. The recent Asian financial crisis, which happened near the end of the sample period, induced large fluctuations in the output growth of Hong Kong and J apan. The sample output growth variances in Table 1.C also suggest that Hong Kong has the highest growth variation. According to the sample correlations, the degree of comovement between the three economies is quite weak. It should be noted that the sample correlations do not account for the dynamic properties of the data and, thus, may give a misleading picture of output interactions. A more vigorous dynamic analysis of the interactions between Hong Kong and the other two economies is given in the following sections.

\section{Output Interaction}

Since the output series are difference-stationary, it is crucial to determine if they tend to move together in the long run. The long-run relationship is interesting for at least two reasons. First, it indicates whether permanent shocks in the three economies are common or idiosyncratic. Second, information about long-run behavior is essential for specifying an appropriate model to analyze short-run interactions. A mis-specified long-run relationship can lead to erroneous inferences on short-run dynamics.

\subsection{Cointegration Test}

The J ohansen (1991) and J ohansen and J uselius (1990) cointergration test is used to test for the presence of an empirical long-run relationship. Define $Y_{t}=\left(Y_{i t}\right)^{\prime}$ as a $3 \times 1$ vector containing Hong Kong, U.S. and J apan output series. The J ohansen test statistics are devised from the sample canonical correlations (Anderson, 1958) between $\Delta Y_{t}$ and $Y_{t-p-1}$, adjusting for all intervening lags. To implement the procedure, we first obtain the least squares residuals from

$$
\Delta Y_{t}=C_{1}+\sum_{i=1}^{p} \gamma_{1 i} \Delta Y_{t-i}+\varepsilon_{1 t}
$$

and

$$
Y_{t-p-1}=C_{2}+\sum_{i=1}^{p} \gamma_{2 i} \Delta Y_{t-i}+\varepsilon_{2 t}
$$

where $C_{1}$ and $C_{2}$ are constant vectors. The lag parameter, $p$, is determined by the AIC. Next, we compute the eigenvalues, $\lambda_{1} \geq \lambda_{2} \geq \lambda_{3}$, of $\Omega_{21} \Omega_{11}^{-1} \Omega_{12}$ with respect to $\Omega_{22}$ and the associated eigenvectors, $v_{1}, v_{2}, v_{3}$, where the moment matrices for $\Omega_{i j}=T^{-1} \sum_{t} \hat{\epsilon}_{i t^{\varepsilon^{\prime}} j t}$ for $i, j=1,2 . \lambda_{i}$ s are the squared canonical correlations between $\Delta Y_{t}$ and $Y_{t-p-1}$ adjusting for all intervening lags. The trace statistic,

$$
t_{r}=-T \sum_{j=r+1}^{3} \ln \left(1-\lambda_{j}\right), \quad 0 \leq r \leq 2
$$

tests the hypothesis that there are at most $r$ cointegration vectors. In testing the hypothesis of $r$ against the alternative hypothesis of $r+1$ cointegration vectors, we use the maximum eigenvalue statistic,

$$
\lambda_{r \mid r+1}=-T \ln \left(1-\lambda_{r+1}\right), \quad 0 \leq r \leq 2 .
$$

The J ohansen test results are reported in Table 2. Both the trace and maximum eigenvalue statistics suggest that there is one cointegrating relationship between the three output series. The estimated 
cointegrating vector, with the coefficient of the Hong Kong variable normalized to one, the J apan output as the second variable, and the U.S. output as the third variable, is $(1,-1.833,0.863)$. The sample statistics for testing the null hypothesis that the coefficients are individually zero are, respectively, 17.59, 15.48, and 11.77 . Under the null hypothesis, these statistics have an asymptotic $\chi^{2}$-(1) distribution. Therefore, all three coefficients are statistically significant at the conventional $5 \%$ level. The adequacy of the selected model (with $p=6$ ) is reflected by the high $p$-values of the diagnostic statistics. In sum, the J ohansen test shows that the output series of Hong Kong, U.S., and J apan are linked together in the long run via an empirical relationship specified by the cointegrating vector. These economies experience common permanent shocks that drive their long-term swings and, thus, share common long-run components in their output data. The result supports the view that these three economies are closely linked via some common permanent shocks.

It is very difficult to interpret the cointegrating vector since the three economies have different output mixes and the three-variable system is inherently atheoretical. However, one crucial implication of the presence of one cointegrating vector is that, in the long run, the dynamics of the output data is driven by two stochastic trend elements. The usual notion of convergence requires the existence of one and only one common stochastic trend (that is two cointegrating vectors in this case) in the system. In this sense, the cointegration test result is at odds with the convergence hypothesis. However, the presence of multiple stochastic trends may be consistent with a more general class of growth models. Durlauf (1989), for example, observes that if unit root persistence is generated by technology, it is likely to have different types of technological shocks affecting various sectors of an economy and, hence, its aggregate output. Further, differences in work habits, corporate cultures, and infrastructures can have persistent effects on output dynamics. Thus, it is not surprising to have more than one integrated technological shock behind output growth.

For the class of endogenous growth models, Lau (1999) offers conditions under which there is more than one common stochastic trend. It appears that the presence of more than one growth factor is a theoretically viable alternative. Durlauf (1989) and Lucke (1998), in fact, document the existence of more than one sector-specific growth factor in the U.S. and German economies. King et. al. (1991) also cast doubt on the claim that the U.S. economy is dominated by a single permanent shock. Thus, the multitude of growth factors revealed by the cointegration test can be appropriately interpreted as an evidence of the plurality of growth factors determining output in the long run.

\subsection{VEC Model}

Given the cointegration result, a vector error correction (VEC), instead of a VAR, specification is used to explore the interactions of output growth. The VEC model is given by

$$
\Delta Y_{t}=\mu+\sum_{i=1}^{p} \Gamma_{i} \Delta Y_{t-i}+\alpha Z_{t-p-1}+\varepsilon_{t}
$$

where $\mu$ is a vector of constants, $Z_{t-p-1}$ is the error correction term given by $\beta Y_{t-p-1}$, and $\beta$ is the estimated cointegrating vector. The responses of output growth to short-term output movements are captured by the $\Gamma_{i}$ coefficient matrices. The $\alpha$ coefficient vector reveals the speed of adjustment to the error correction term, which measures the deviation from the empirical long-run relationship. For parsimony 
considerations, only variables with significant coefficient estimates are included. The Hong Kong output growth model is presented in Table $3 .^{6}$

The output growth appears to have a complex dynamic structure. The Hong Kong output growth is affected by its own history up to the past five quarters. Both the U.S. and J apan lagged growth rates have a significant positive impact on Hong Kong output. Compared with the U.S., J apan lagged output growth, according to the estimated coefficients, appears to have a larger and more extended effect on the Hong Kong economy. The error correction term has a significantly negative coefficient indicating the Hong Kong output adjusts to deviations from the empirical long-run relationship in a stable manner. ${ }^{7}$ Using the Granger causality terminology in the VEC framework (Granger and Lin, 1995), the Hong Kong output is caused by the other two economies. The result is consistent with the view that the two large economies exert considerable economic influence on the small open economy of Hong Kong.

The adjusted $R^{2}$ of the Hong Kong output growth specification is $74.77 \%$. The diagnostic statistics indicate that the residuals are well behaved and pass the J arque-Bera normality test. As a heuristic way to compare the relative explanatory power of the lagged variables, we compute the adjusted $R^{2} \mathrm{~S}$ of several specifications. It turns out that the lagged Hong Kong variables alone yield an adjusted $R^{2}$ of $54.73 \%$. The addition of the error correction term increases the adjusted $R^{2}$ marginally to $58.76 \%$. Interestingly, the specification that includes only the lagged U.S. and J apan variables has an adjusted $R^{2}$ of $5.82 \%$. Apparently, Hong Kong output growth dynamics are mainly determined by its own past history. The output histories of the three economies display some kind of complementary effects in explaining growth dynamics in Hong Kong. Their combined explanatory power, as given by the adjusted $R^{2}$, is $74.77 \%$ and is larger than the sum of those from the specifications that contain the explanatory variables separately.

\subsection{Impulse Responses and Forecast Error Variance Decomposition}

To obtain a better understanding of Hong Kong output dynamics, we use the VEC specification in the previous subsection to evaluate the response of Hong Kong to various output shocks and assess the individual shocks' contributions to the output uncertainty. The generalized impulse response and forecast error variance decomposition techniques (Pesaran and Shin, 1998) are used. Unlike the traditional approach based on Cholesky decomposition and orthogonalized shocks, the Pesaran-Shin approach yields unique impulse response functions and forecast error variance decompositions that are invariant to the ordering of variables. Only in the limiting case of a diagonal error variance matrix do the traditional and the generalized approaches coincide.

Suppose $Y_{t}$ has a VAR representation:

$$
Y_{t}=C+\sum_{i}^{p} \Phi_{i} Y_{t-i}+\varepsilon_{t}
$$

6 For references, the VEC specifications of the U.S. and J apan are given in the Appendix.

7 As indicated in the Appendix, the error correction term has no effect on U.S. growth. It is the small economy, not the large economy, which adjusts to the deviation. 
where $C$ is a vector of constant and $\varepsilon_{t}$ is a vector of innovation with $\mathrm{E}\left(\varepsilon_{t}\right)=0$ and $\mathrm{E}\left(\varepsilon_{t} \varepsilon_{t}^{\prime}\right)=\Sigma=\left(\sigma_{i j}\right)$. The generalized impulse response of $Y_{t+n}$ with respect to a unit shock to the $j$-th variable at time $t$ is given by

$$
\frac{B_{n} \Sigma e_{j}}{\sigma_{j j}}, \quad n=0,1,2, \ldots
$$

where $B_{n}=\Phi_{1} B_{n-1}+\Phi_{2} B_{n-2}+\ldots \ldots .+\Phi_{p} B_{n-p^{\prime}} n=1,2, \ldots \ldots, B_{0}=I$, and $B_{n}=0$ for $n<0 . e_{j}$ is a selection vector with unity as its $j$-th element and zeros elsewhere. The portion of variable $i$ 's $n$-th periods ahead forecast error variance which is attributable to innovations in the $j$-th variable can be computed as

$$
\frac{\sigma_{i j}^{-1} \sum_{l=0}^{n}\left(e_{i}^{\prime} B_{l} \Sigma e_{j}\right)^{2}}{\sum_{l=0}^{n} e_{i}^{\prime} B_{l} \Sigma B_{l}^{\prime} e_{i}} \quad i, j=1,2,3 .
$$

It is shown that (7) and (8) are valid for a system of cointegrated variables. See Pesaran and Shin (1998) for a more detailed discussion.

The generalized impulse response functions of Hong Kong output with respect to a unit shock in the Hong Kong, U.S., and J apan equations are depicted in Figure 2. Both the U.S and J apan output shocks have a sizable and sustained impact on Hong Kong output. In the first few quarters, Hong Kong responds forcefully to a foreign output shock. The effect of a foreign shock cumulates and reaches its peak in four to five years. After that, the foreign influence varies for a few years and, then, stays at a steady level about three to four times the magnitude of the initial shock. The pattern is in contrast to the effect of Hong Kong's own output shocks. In response to shocks to its own economy, Hong Kong output first oscillates and, then, stabilizes. The long-term effect of a domestic output shock is slightly larger than the magnitude of the initial shock. Relatively speaking, the Hong Kong economy displays a stronger response to shocks emanating from the U.S. and J apan than those from the local economy.

The results of the generalized forecast error variance decomposition are graphed in Figure 3. While the impulse responses trace the effect of a shock over time, the forecast error variance decomposition analysis assesses the relative contributions of domestic and foreign shocks to the output uncertainty in Hong Kong. For short-term horizons, the uncertainty of forecasting Hong Kong output is mostly due to domestic shocks. In the case of one to four-quarter ahead forecasts, shocks to the domestic economy account for $80 \%$ to $90 \%$ of the forecasting uncertainty. The proportion of output uncertainty explained by the domestic shock, however, is decreasing with the forecasting horizon. Beyond the four-year horizon, the domestic shock accounts for slightly more than one-third of the Hong Kong output uncertainty. The contributions of both the U.S. and J apan shocks start at a low level and grow steadily as the horizon increases. Over a long forecasting horizon (say, over four years), shocks originating from the U.S. and J apan accounted for slightly over one- quarter and one-third of the Hong Kong output forecasting uncertainty, respectively.

\subsection{Common Cyclical Movement}

In this subsection we examine whether the output series share some common cyclical movements. So far, we examine the comovement of the nonstationary output components and the interaction of output growth. However, there is no direct evidence on the presence of a common business cycle among the 
three economies. Engle and Kozicki (1993) propose a common feature test to detect the presence of common stochastic elements. The intuition behind the common feature analysis is as follows. Suppose the elements of $\Delta Y_{t}$ share a common temporal dynamic. Then, by forming an appropriate linear combination of $\Delta Y_{i t}{ }^{\prime}$ s, we can eliminate the effect of the common component. Thus, the presence of a common cycle, which is routinely measured by serial correlation in the literature, implies the existence of a linear combination of $\Delta Y_{i t}$ 's that is not correlated with the past information set. Vahid and Engle (1993) devise a procedure to test for common serial correlation cycles in the presence of cointegration. The Vahid-Engle procedure amounts to finding the sample canonical correlations between $\Delta Y_{t}$ and $W_{t}=$ $\Delta Y_{t-1}^{\prime}, \Delta Y_{t-2}^{\prime}, \ldots, \Delta Y_{t-p^{\prime}}^{\prime} Z_{t-1}$, where the error correction term $Z_{t-1}$ is included to control for the cointegration effect on the test for common features. The test statistic for the null that there are at least s common feature (co-feature) vectors is

$$
C(p, s)=-(T-p-1) \sum_{j=1}^{s} \log \left(1-\lambda_{j}\right)
$$

where $\lambda_{j}$ is the $j$-th smallest squared canonical correlation coefficient between $\Delta Y_{t}$ and $W_{t^{\prime}} T$ is the sample size, and $p$ is the lag parameter. Under the null hypothesis, $C(p, s)$ has an asymptotic $\chi^{2}$ distribution with $s^{2}+s n p+s r-s n$ degrees of freedom with $n=$ number of variable in the system and $r$ is the number of cointegrating vector included in $W_{t}$. See Vahid and Engle (1993) for a more detailed discussion.

The common feature test results are reported in Table 4. The lag parameter identified for the J ohansen procedure is used to compute the $C(p, s)$ statistic. The statistics for both $s=3$ and $s=2$ are significant but the one for $s=1$ is not. Thus, there is one common feature vector. The three output series share some common business cycles, which are driven by two temporal dynamic processes. In addition to the presence of some common long-run components in their output series, the short-run variation in the rates of growth is determined by some common transitory fluctuations.

\subsection{Discussion}

The results of the trivariate system analysis are consistent with the view that the Hong Kong economy is closely linked to the U.S. and J apan. The three economies share some common long-run and shortterm components. According to the VEC specification, Hong Kong's own growth experience plays an important role in explaining the variation in its own output movements. The generalized impulse response and forecast error variance decomposition analyses confirm U.S. and J apan influences on the Hong Kong economy. The generalized impulse response exercise indicates that foreign output shocks have amplified effects on the Hong Kong economy - a result that is consistent with Hong Kong's reliance on its external sector. Nonetheless, the difficulty in forecasting Hong Kong output, especially in short horizons, is mainly owing to domestic shocks. Thus, even for a small open economy such as Hong Kong, domestic elements can still be important forces behind its output variability and uncertainty. ${ }^{8}$

One interesting observation is the relative dependency of Hong Kong on the U.S. and J apan. Even though the U.S. dollar is the anchor currency of Hong Kong's currency board system, the U.S. influence

8 Cheung and Westermann (2000) also documented that, contrary to the common belief, Austrian output is mainly affected by its own output shocks rather than German and U.S. shocks. 
on Hong Kong does not appear to be stronger than the J apanese. The procedures considered in the previous subsections capture different aspects of output interactions. In all cases Hong Kong responds to developments in the U.S. and J apan. However, there is no definite evidence that, compared with J apan, the U.S. has an overwhelming and dominating impact on Hong Kong. Even though the U.S. exhibits a stronger influence in the framework of generalized impulse analysis, both the generalized forecast error variance decomposition and VEC specification suggest that J apan may have a stronger influence on the Hong Kong economy. Thus, the exchange rate linkage by itself does not necessarily mean a small open economy will be dominated by a large economy.

\section{Macroeconomic Variables ${ }^{9}$}

In the previous section, a time series framework is used to examine Hong Kong output dynamics. The framework is statistically oriented and documents the transmission of foreign shocks to Hong Kong. Nonetheless, there is no information on the channels through which the output shocks are propagated. It is widely believed that international output shocks are largely transmitted through trade and financial linkages. For example, a flourishing U.S. economy stimulates output in Hong Kong via the trade channel by boosting the demand for Hong Kong's exports. The trade linkage usually portrays a positive correlation between output across economies. On the other hand, through the financial linkage, a stronger U.S. economy depresses the Hong Kong economy by forcing up interest rates and the exchange rates in both the U.S. and Hong Kong. Of course, if monetary easing is the reason for the strength in the U.S. economy, then the financial linkage may operate in a different direction and raise output in Hong Kong. Thus, depending on the source of growth, the trade and financial effects may be different.

It may be argued that the lagged output variables in the VEC specification for Hong Kong output growth are just proxies for other macroeconomic variables which represent the underlying transmission mechanism. The significance of the lagged output terms can be attributed to their ability to capture the effects of other macroeconomic variables on growth. To investigate such a possibility, we include a number of trade and financial variables in the growth equation. Specifically, the basic VEC model (equation 5) is modified to

$$
\Delta Y_{t}=\mu+\sum_{i=1}^{q} \lambda_{i} W_{t-i}+\sum_{i=1}^{p} \Gamma_{i} \Delta Y_{t-i}+\alpha Z_{t-p-1}+\varepsilon_{t}
$$

where $W_{t-i}$ is a $n \times 1$ vector containing trade and financial variables and $\lambda_{i}$ is the associated coefficient matrix. As in the previous section, our focus is the Hong Kong growth equation.

The variables to be included in the $W_{t-i}$ vector are (a) Hong Kong's per capita real exports (hereafter, exports for short) to China, the U.S., and J apan, (b) Hong Kong's real effective exchange rates, (c) real equity indexes in Hong Kong, the U.S., and J apan, and (d) real interest rates in Hong Kong, the U.S., and J apan. ${ }^{10}$ The export data are used to capture the trade effect while the remaining financial variables are proxies for the financial channel. The following strategy is used to investigate the effects of the

9 Part of this section benefits greatly from exchanges with Guy Meredith.

10 A detailed data description is given in the Appendix. 
macroeconomic variables on Hong Kong growth dynamics. First, we include these variables one at a time in $W_{t-i}$ to study their individual effects. For each variable, the values of the past four quarters are considered. Next, the significant variables obtained from the previous stage are collected in $W_{t-i}$ and the resulting insignificant variables are then deleted. This strategy helps preserve the degree of freedom and the effective number of observations. The preservation feature is relevant for this exercise since the sample size under consideration is not large. The estimation results are summarized in Table 5.

\subsection{Individual Trade and Financial Linkages}

The VEC specification in Table 3 is repeated in Table 5 as Model 1 for comparison purposes. Model 2 is the case in which only significant trade variables are included in the $W_{t-i}$ vector. Conditioning on the lagged output variables, the lag-one to lag-four exports to U.S. variables are not significant. Only those to $\mathrm{J}$ apan and Mainland China help explain the variation in Hong Kong output growth. Both the first and second lags of exports to J apan have a positive impact on Hong Kong. That is, stronger exports to $\mathrm{J}$ apan raise output in Hong Kong. The estimated coefficient of the exports to China is a bit puzzling. It is significantly negative and, thus, implies exports to China will depress the economic activity in Hong Kong. Such an interpretation, however, is not consistent with, for example, the usual trade effect argument. On the other hand, the negativity result is not likely to be a statistical incident because, as discussed below, a similar negative coefficient is present in specifications involving other trade and financial variables. A possibility is that the negative coefficient is due to some complex interactions between this export variable and other right-hand-side variables.

The inclusion of trade variables does not have much impact on the performance of the lagged output variables. The coefficients of the lagged output variables in Model 1 and Model 2 are very similar. They have the same signs and show only some slight differences in their magnitudes. Further, both specifications pass the portmanteau $Q$ and J arque-Bera tests. Apparently, the information content of the lagged output variables on Hong Kong economic growth does not overlap much with that of the trade variables. The two groups of variables are capturing different aspects of the output growth dynamics. With the three trade variables added to the basic VEC model, the adjusted $\mathrm{R}^{2}$ is lifted by $5 \%$.

Model 3 adds significant financial variables to the basic Model 1. A stronger Hong Kong dollar brings down economic activities. Both the first and third lags of Hong Kong real effective exchange rate have a negative coefficient. ${ }^{11}$ The Hong Kong real interest rate also has a negative impact on the economy. ${ }^{12}$ Interestingly, in the presence of Hong Kong real exchange rates, the U.S. and J apan interest rate variables do not have any incremental explanatory power. On real equity market indexes, the U.S. index is insignificant (hence, not reported), the Hong Kong one has a negative sign, and the J apan one has a positive sign. As revealed in the subsequent analysis, the performance of these two real equity indexes is not stable across specifications.

11 The inclusion of the third lag is necessary for obtaining good diagnostic statistics.

12 The effects of real effective exchange rates and real interest rates on Hong Kong output are also documented in Peng (2000). 
The financial variables improve the goodness of fit and advance the adjusted $R^{2}$ to $83.24 \%$. At the same time, the coefficients of the lagged output variables under Model 1 and Model 3 are qualitatively the same. The inclusion of the financial variables does not materially change the estimated interaction between Hong Kong output growth and the lagged output variables. Again, it appears that the information in the financial variables that is related to Hong Kong output growth is largely differentiated from the output variables.

\section{2 "Combined" Effect and Extensions}

The "combined" effect of trade and financial variables is represented by Model 4, which passes the serial correlation Q-test and the J arque-Bera normality test. When both the trade and financial variables are included in $W_{t-i^{\prime}}$ the exports to Mainland China term is the only significant trade variable. The two exports to J apan variables, which are reported under Model 2, become insignificant. On the financial side, the Hong Kong equity index drops out and the U.S. one shows up significantly. Further, the J apan real interest rate has a significant negative coefficient. For the lagged output, the coefficients of the lagged Hong Kong and J apan growth variables are smaller than those under Model 1. However, these two coefficients are still significantly positive. Besides these variables, the other coefficient estimates are quite similar to those reported in the previous models. The trade and financial variables together elevate the adjusted $R^{2}$ from $74.77 \%$ (Model 1 ) to the level of $89.26 \%$.

Two extensions of Model 4 are considered. The first extension is related to the role of Hong Kong as an entrepôt. Given the importance of entrepôt trade, we decomposed the Hong Kong trade data into two components - the domestic exports and re-exports - and examined their individual roles in explaining Hong Kong output growth. Again, each dis-aggregated export series is added to Model 4 individually. The result is given in Model 5. For all the dis-aggregated export series, only the domestic exports to $J$ apan and re-exports to the U.S. have incremental explanatory power. Both variables have a positive effect on the Hong Kong economy. It is not sure why the dis-aggregated export series have differential effects across foreign markets. An interesting future research topic is to explore the micro implications of dis-aggregated trade data on growth.

The second extension is on the effect of real exchange rates. The real effective exchange rate used in Models 3 to 5 is a weighted exchange rate. To investigate the individual real exchange rate effect, we expanded Model 5 to include the dollar-based and yen-based real exchange rates. It turns out that only the lagged dollar-based real exchange rate has incremental explanatory power. The estimation result is reported in Table 6. Apparently, the presence of the dollar-based real exchange rate lowers the effect of the first lag of the Hong Kong real effective exchange rate. The two extensions - the use of dis-aggregated export data and country-specific real exchange rates - raise the adjusted $R^{2}$. In fact, both Model 5 and Model 6 have an adjusted $R^{2}$ higher than $90 \%$ and pass the serial correlation and normality diagnostic tests.

The maximum absolute prediction error of each specification is given at the bottom of Table 5 . It ranges from $\mathbf{0 . 9 8 \%}$ (Model 6) to $2.77 \%$ (Model 1). The maximum absolute prediction error of Model 1 occurs at 1999:II. The presence of either the trade or the financial variables reduces the maximum prediction error in general and the prediction error at 1999:II in particular. The actual and fitted values from Model 1 to 
Model 6 are graphed in Figure 4 . As indicated by the adjusted $R^{2} \mathrm{~s}$, the six specifications track the growth pattern pretty well. Even for Model 1 , which has the lowest adjusted $R^{2}$, the fitted values follow most of the turning points in the output growth series.

\subsection{Discussion}

Overall, the trade and financial variables improve the ability to explain Hong Kong growth dynamics. However, the addition of these variables to the basic VEC specification has little impact on the performance of the lagged output variables. The most obvious effects are on the first lagged growth rates. The trade and financial variables tend to compete with the first lagged Hong Kong and J apan growth rates. The coefficient of the first lagged Hong Kong growth rate under Model 6 is 0.19 , which is less than one half of the value under Model 1. The trade and financial variables reduce the coefficient of the first lagged J apan growth from 0.66 (Model 1) to 0.43 (Model 4). On the other hand, the presence of these variables magnifies the influence of U.S. output - the coefficient of the first lagged U.S. growth increases from 0.75 (Model 1) to 0.91 (Model 5). Other than these three coefficients, the other output coefficients are quite stable across different model specifications. Among the trade and financial variables themselves, the coefficients of the real effective exchange rate and Hong Kong real interest rate are the most stable ones across models. Further all these model specifications pass both the portmanteau Qtest and normality test.

While the trade and financial linkages are usually perceived to be the main channels through which developments in the U.S. and J apan have an impact on Hong Kong, the stability of the lagged output coefficients suggests that there are other important shock transmission channels as captured by output (growth) variables. If the lagged output variables are proxies for the trade and financial variables, then the former will become insignificant and be displaced when the latter is included in the regression. However, we do not observe the displacement effect in Table 5 . There is only weak evidence supporting the hypothesis that the lagged output variables are proxies for the trade and financial variables and derive their explanatory power from the trade and financial effects.

In fact, the group of lagged output variables have a better explanatory power than the group of trade and financial variables. For instance, when we used only the trade and financial variables listed under Model 6 as regressors, the adjusted $R^{2}$ is $15.86 \%$. Recall that Model 1 which contains only lagged output (growth) variables as regressors has an adjusted $R^{2}$ of $74.77 \%$ ! Further, the sum of the component adjusted $R^{2} \mathrm{~S}$ is $15.86 \%+74.77 \%=90.63 \%$, which is less than the adjusted $R^{2}$ of Model 6 . Evidently, the explanatory powers of these two groups of regressors are complementary and the group of output variables contains more information about the Hong Kong growth dynamics than the group of trade and financial variables.

\section{Concluding Remarks}

Per capita real output data are used to examine the effects of the U.S. and J apanese economies on Hong Kong. It is found that the three economies share common long-run and short-run movements. The cointegration result is supportive of a growth model with multiple growth factors. In accordance 
with the usual perception of a small open economy, output in Hong Kong is Granger-caused by developments in the U.S. and J apan. Compared with domestic shocks, output shocks originating from the U.S. and J apan have larger impacts on Hong Kong. Even though the U.S. dollar is the anchor currency of the Hong Kong linked exchange rate system, there is no consistent evidence that the U.S. influence is stronger than the $\mathrm{J}$ apanese one. The empirical results, in fact, show that substantial parts of the Hong Kong output uncertainty and output dynamics are accounted for by domestic factors.

The basic VEC model is extended to incorporate the trade and financial variables that are commonly believed to facilitate output shock transmission. It is found that the additional variables provide incremental explanatory power and raise the adjusted $R^{2}$ from $74.77 \%$ to $93.24 \%$. Nonetheless, the information on output dynamics embedded in the trade and financial variables appears to be a complement to rather than a substitute for the information contained in output data. When the set of regressors includes (a) lagged Hong Kong output growth variables, (b) lagged U.S. and J apan output growth variables, and (c) trade and financial variables, the adjusted $R^{2} \mathrm{~S}$ of the corresponding models are $57.43 \%, 5.82 \%$, and $15.86 \%$, respectively. Thus, the explanatory power of the trade and financial variables is lower than the lagged Hong Kong growth rates but higher than the foreign output variables.

A few observations are in order. First, while the exchange rate arrangement offers an additional shock transmission passage, the VEC specification does not reveal that the U.S. influence on Hong Kong is stronger than the $\mathrm{J}$ apanese one. ${ }^{13}$ Further, the models incorporating trade and financial variables do not show a dominating U.S. role. It is quite unexpected to find the relatively minor function of the U.S. economy given its image as the locomotive of the world economy. Apparently, the linked exchange rate system does not subject Hong Kong to undue U.S. influences.

Second, output shocks can propagate across economies through channels other than the trade and financial linkages. In the presence of selected trade and financial variables, the performance of the output variables (including the foreign ones) is mostly the same as those in the basic VEC model. Thus, there are transmission mechanisms captured by these output variables that are very different from those related to the trade and financial variables. The local financial variables have a prominent position in the list of significant variables. Specifically, the real effect exchange rate and the real interest rate display a rather stable relationship with Hong Kong output growth. The influences of nation-specific variables such as exports, equity index, real exchange rate, and interest rate do not have a consistent pattern across the economies. For instance, while domestic exports to J apan boost output in Hong Kong, it is the re-exports to the U.S. that stimulate Hong Kong economic activity. An interesting future research topic is to conduct a more detailed analysis of the economic channels through which external shocks affect Hong Kong. Given the close economic ties between Hong Kong and Mainland China, future studies on the topic should benefit from using more extensive China data. Unfortunately, due to paucity and quality considerations, the current exercise uses only limited economic data from China.

Finally, even for a small open economy like Hong Kong, local factors remain a key determinant of its output dynamics. Though the cointegration and common feature tests show that there are some common

13 Kwan et al. (1999), for example, attributes the strength of J apan output shock transmission to J apan's overseas investment strategy. 
long-run and short-run forces driving the output in the three economies, Hong Kong exhibits considerable idiosyncratic behavior. For instance, Hong Kong's own lagged growth rates can explain more than one half of its output growth variation. The model that has both lagged Hong Kong growth and real interest rates as regressors has an adjusted $R^{2}$ of about $71 \%$. In addition, the domestic output shock is responsible for $80 \%$ to $90 \%$ of output uncertainty in the short run, and for more than $33 \%$ of output uncertainty in the long run. Thus, domestic economic measures can have non-trivial implications for the economy, and policies that reduce economic uncertainties in the local economy would stabilize output and reduce overall variability. 


\section{References}

Anderson, T.W., (1958), An Introduction in Multivariate Statistical Analysis, Wiley: New York.

Baxter, M. and A.C. Stockman, (1989), "Business Cycles and the Exchange Rate Regime: Some International Evidence," Journal of Monetary Economics 23, 377-400.

Berger, H., J . de Haan and J .-E. Sturm, (2000), "An Empirical Investigation Into Exchange Rate Regime Choice and Exchange Rate Volatility," CESifo Working Paper \#263.

Campbell, J. and N.G. Mankiw, (1989), "International Evidence on the Persistence of Economic Fluctuations," Journal of Monetary Economics 23, 319-333.

Canova, F. and H. Dellas, (1993), "Trade Interdependence and International Business Cycle," Journal of International Economics 34, 23-49.

Canova, F. and J . Marrinan, (1998), "Sources and Propagation of International Output Cycles: Common Shocks or Transmission," Journal of International Economics 46, 133-166.

Cheung, Y.-W., (1994), "Aggregate Output Dynamics in the Twentieth Century," Economics Letters 45, $15-22$.

Cheung, Y.-W. and K.S. Lai, (1993), "Finite Sample Sizes of J ohansen's Likelihood Ratio Tests for Cointegration," Oxford Bulletin of Economics and Statistics 55, 313-328.

Cheung, Y.-W. and K.S. Lai, (1995), "Lag order and Critical Values for the Augmented Dickey-Fuller Test," Journal of Business \& Economic Statistics 13, 277-280.

Cheung, Y.-W., J . He and L. Ng, (1994), "Pacific Basin Stock Markets and Real Activity," Pacific-Basin Finance Journal 2, 349-373.

Cheung, Y.-W. and F. Westermann, (1999a), "Output Dynamics of the G7 Countries: Stochastic Trends and Cyclical Movements," manuscript, University of California, Santa Cruz.

Cheung, Y.-W. and F. Westermann, (1999b), "An Analysis of German Effects on the Austrian Business Cycles," Weltwirtschaftliches Archiv 135, 522-531.

Cheung, Y.-W. and F. Westermann, (2000), "Does Austria Respond to the German or the U.S. Business Cycles?" International Journal of Finance \& Economics 15, 33-42.

Cole, H. and M. Obstfeld, (1991), "Commodity Trade and International Risk Sharing," Journal of Monetary Economics 28, 3-24. 
Devereux, M. and C. Engel, (1998), "Fixed vs. Floating Exchange Rates: How Price Setting Affects the Optimal Choice of Exchange-Rate Regime," NBER Working Paper \#6867.

Dornbusch, R., (1983), "Flexible Exchange Rages and Interdependence," International Monetary Fund Staff Papers 30, 3-30.

Durlauf, S.N., (1989), "Output Persistence, Economic Structure, and the Choice of Stabilization Policy" Brookings Papers on Economic Activity 2, 69-136.

Durlauf, S.N. and D.T. Quah, (1999), "The New Empirics of Economic Growth," in Handbook of Macroeconomics, J .B. Taylor and M. Woodford (eds.), Chapter 4, 231-304, Amsterdam: North-Holland Elsevier Science.

Elliott, G., T.J . Rothenberg and J.H. Stock, (1996), "Efficient Tests for an Autoregressive Unit Root," Econometrica 64, 813-836.

Engle, R.F. and S. Kozicki, (1993), "Testing for Common Features," Journal of Business and Economic Statistics 11, 369-395.

Flood, R.P. and R. J . Hodrick, (1986), "Real Aspects of Exchange Rate Regime Choice with Collapsing Fixed Rates," Journal of International Economics 21, 215-232.

Flood, R.P. and A. K. Rose, (1995), "Fixing Exchange Rates: A Virtual Quest for Fundamentals," Journal of Monetary Economics 36, 3-37.

Frankel, J .A. and M.L. Mussa, (1980), "The Efficiency of the Foreign Exchange Market and Measures of Turbulence," American Economic Association Papers and Proceedings 70, 374-381.

Granger, C.W.J . and J .L. Lin, (1995), "Causality in the Long Run," Econometric Theory 11, 530-536.

Hutchison, M. and C.E. Walsh, (1992), "Empirical Evidence on the Insulation Properties of Fixed and Flexible Exchange Rates: The J apanese Experience," Journal of International Economics 32, 241-263.

J ao, Y.C., (1998), "The Working of the Currency Board: The Experience of Hong Kong 1935-1997," Pacific Economic Review 3, 219-241.

J ohansen, S., (1991), "Estimation and Hypothesis Testing of Cointegration Vectors in Gaussian Vector Autoregressive Models," Econometrica 59, 1551-1581.

J ohansen, S. and K. J uselius, (1990), "Maximum Likelihood Estimation and Inference on Cointegrationwith Applications to the Demand for Money," Oxford Bulletin of Economics and Statistics 52, 169-210.

Kim J ., (2000), "The Relationship Between the Monetary Regime and Output Volatility: A Multivariate GARCH_M Model of the J apanese Experience 1919-1996," Japan and the World Economy 12, 49-69. 
King, R.G., C.L. Plosser, J .H. Stock and M.W. Watson, (1991), "Stochastic Trends and Economic Fluctuations," American Economic Review 81, 819-840.

Kwan, N., S. Wong and A. Kwok, (1999), "J apan's Economic Role in Asia," Research Memorandum 17/99, Hong Kong Monetary Authority.

Kydland, F.E. and E.C. Prescott, (1982), "Time to Build and Aggregate Fluctuations," Econometrica 50, 1345-1370.

Lastrapes, W.D. and F. Koray, (1990), "International Transmission of Aggregate Shocks under Fixed and Flexible Exchange Rate Regimes: United Kingdom, France, and Germany, 1959 to 1985," Journal of International Money and Finance 9, 402-423.

Lau, S.H.P., (1999), "I(0) In, Integration and Cointegration Out: Time Series Properties of Endogenous Growth Models," Journal of Econometrics 93, 1-24.

Lee, K., (1998), "Cross-Country Interdependencies in Growth Dynamics: A Model of Output Growth in the G7 Economies, 1964-1994," Weltwirtschaftliches Archiv 134, 367-403.

Lucke, B., (1998), "Productivity Shocks in a Sectoral Real Business Cycle Model for West Germany," European Economic Review 42, 311-327.

Lumsdaine, R.L, and E.S. Prasad, (1997), "Identifying the Common Component in International Economic Fluctuations," NBER Working Paper \#5984.

Marston, R., (1985), "Stabilization Policies in Open Economies," in Handbook of International Economics, Vol. 2, R.W. J ones and P.B. Kenen (eds.), Amsterdam: North-Holland.

Melvin, M., (1985), "The Choice of an Exchange Rate Regime and the Macroeconomic Stability," Journal of Money Credit and Banking 17, 467-478.

Mundell, R.A., (1961), "A Theory of Optimum Currency Areas," American Economic Review 51, 657-675.

Peng, W., (2000), "A Monetary Conditions Index for Hong Kong," Research Memorandum 05/2000, Hong Kong Monetary Authority.

Pesaran, H.H. and Y. Shin, (1998), "Generalized Impulse Response Analysis in Linear Multivariate Models" Economics Letters 58, 17-29.

Romer, P.M., (1986), "Increasing Returns and Long-Run Growth," Journal of Political Economy 94, 1002-1037.

Vahid, F. and R.F. Engle, (1993), "Common Trends and Common Cycles," Journal of Applied Econometrics 8, 341-360. 


\section{Table 1. Descriptive Statistics}

\section{A. Augmented Dickey-Fuller-GLS Test for Levels}

\begin{tabular}{lccccr} 
& No. of lags & Test Statistics & $Q(4)$ & $Q(8)$ & Q(12) \\
\cline { 2 - 6 } & 5 & -2.301 & $4.39(0.36)$ & $5.64(0.69)$ & $6.77(0.87)$ \\
HK & 3 & -2.254 & $1.16(0.88)$ & $8.21(0.41)$ & $11.91(0.45)$ \\
US & 2 & -1.581 & $0.67(0.96)$ & $0.88(0.99)$ & $8.27(0.76)$
\end{tabular}

\section{B. Augmented Dickey-Fuller-GLS Test for First Differences}

\begin{tabular}{lccccr} 
& No. of lags & Test Statistics & $Q(4)$ & $Q(8)$ & Q(12) \\
\cline { 2 - 6 } HK & 4 & $-3.851^{* *}$ & $5.96(0.20)$ & $6.60(0.58)$ & $7.90(0.79)$ \\
JP & 2 & $-2.157^{*}$ & $0.69(0.95)$ & $8.42(0.39)$ & $11.54(0.48)$ \\
US & 1 & $-2.295^{* *}$ & $1.32(0.86)$ & $1.61(0.99)$ & $10.18(0.60)$
\end{tabular}

\section{Variance and Correlation (First Differences)}

$\begin{array}{llll}\text { HK } & 0.001172 & (H K, J P) & 0.083002 \\ \text { JP } & 0.000086 & \text { (HK, US) } & -0.13280 \\ \text { US } & 0.000026 & \text { ( P, US) } & -0.18342\end{array}$

Note: ADF-GLS test with a time trend is applied to the Hong Kong (HK), J apan (J P) and U.S. (US) per capita real GDP data. The test with only an intercept is applied to the differenced output data. Q(k) gives the Ljung-Box statistic constructed from the first $k$ autocorrelation coefficients. The parentheses next to the $Q(k)$ statistics contain their $p$-values. The lag parameter is chosen by the Akaike information criterion. The Cheung and Lai (1995) finite sample critical values are used and significance at the $5 \%(10 \%)$ level is indicated by $* *(*)$. 


\section{Table 2. Cointegration Test Results}

\section{A. Johansen Test}

\begin{tabular}{ccc}
$\mathrm{H}(0)$ & M. statistics & Trace statistics \\
\hline$r=2$ & 0.0057 & 0.0057 \\
$r=1$ & 16.74 & 16.75 \\
$r=0$ & $38.30 *$ & $55.05^{*}$
\end{tabular}

B. Cointegrating Vector

\begin{tabular}{ccc}
$H K$ & $J P$ & US \\
\hline 1 & -1.833 & 0.863 \\
$(17.59)$ & $(15.48)$ & $(11.77)$
\end{tabular}

\section{Diagnostic Analysis}

$\begin{array}{lccc} & Q(4) & Q(8) & Q(12) \\ \text { HK } & 4.26(0.37) & 9.87(0.27) & 13.40(0.34) \\ \text { JP } & 0.85(0.93) & 8.73(0.37) & 12.04(0.44) \\ \text { US } & 0.57(0.97) & 4.12(0.85) & 6.71(0.88)\end{array}$

Note: The lag parameter is equal to 6 . The Cheung and Lai (1993) finite sample critical values are used and significance at the $5 \%$ level is indicated by *. The statistics given underneath the cointegrating vector test the hypothesis that the cointegrating elements are individually zero. $Q(k)$ gives the Ljung-Box statistic constructed from the first $k$ autocorrelation coefficients. The parentheses next to the $\mathrm{Q}(k)$ statistics contain their $\mathrm{p}$-values. 


\section{Table 3. The VEC Specification for Hong Kong Growth Rates}

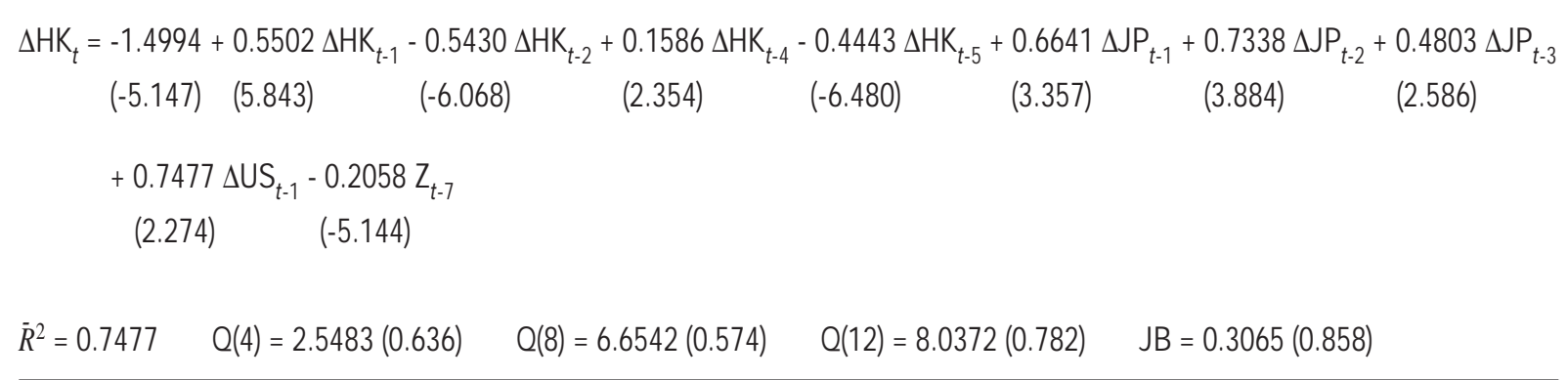

Notes: The effective sample period is 85:4 - 99:2. The definition of the variables is HK = Hong Kong's Per Capita GDP at 1990 prices, J P $=$ J apan's Per Capita GDP at 1990 prices, US $=$ United States' Per Capita GDP at 1996 prices, and $\Delta$ is the first difference operator. $Z_{t}=H_{t}-1.833 \mathrm{JP}_{t}+0.863 \mathrm{US}_{t}$ is the error correction term. Values in parentheses underneath the coefficient estimates are the $t$-statistics. $Q(k)$ gives the Ljung-Box statistic constructed from the first $k$ autocorrelation coefficients. J B gives the J arque-Bera normality test statistic. The parentheses next to the $Q(k)$ and J B statistics contain their $p$-values.

\section{Table 4. Common Feature Test Results}

\begin{tabular}{lccc}
\hline Null Hypothesis & $\begin{array}{c}\text { Squared Canonical } \\
\text { Correlation }\end{array}$ & $\begin{array}{c}\text { Statistics } \\
C(p, s)\end{array}$ & Degrees of Freedom \\
$S=1$ & 0.3927 & 27.4316 & 17 \\
$S=2$ & 0.6295 & $82.0428 *$ & 46 \\
$S=3$ & 0.8152 & $174.9151^{*}$ & 54 \\
\hline
\end{tabular}

Note: $S$ gives the number of common features. Under the null, $C(p, s)$ has an asymptotic $x^{2}$ distribution with $s^{2}+s n p+s r-s n$ degrees of freedom, where in this exercise $n=3, p=6$, and $r=1$. * indicates significance at the $5 \%$ level. 
Table 5. The Augmented VEC Models for Hong Kong Growth Rates

\begin{tabular}{|c|c|c|c|c|c|c|}
\hline Variables & Model 1 & Model 2 & Model 3 & Model 4 & Model 5 & Model 6 \\
\hline \multirow[t]{2}{*}{ C } & $-1.4994^{*}$ & -1.7731* & $-1.3075^{*}$ & $-1.5180 *$ & $-1.8060 *$ & $-1.8948 *$ \\
\hline & $(-5.147)$ & $(-6.280)$ & $(-4.408)$ & $(-6.064)$ & $(-8.065)$ & $(-9.000)$ \\
\hline \multirow{2}{*}{$\Delta \mathrm{HK}_{t-1}$} & $0.5502 *$ & $0.3721 *$ & $0.4084 *$ & $0.2357 *$ & $0.2017 *$ & $0.1914 *$ \\
\hline & $(5.843)$ & (3.708) & $(4.745)$ & (3.039) & $(2.960)$ & (2.993) \\
\hline \multirow[t]{2}{*}{$\Delta \mathrm{HK}_{t-2}$} & $-0.5430 *$ & $-0.7096 *$ & $-0.5295^{*}$ & $-0.5490 *$ & $-0.6956 *$ & $-0.6606 *$ \\
\hline & $(-6.068)$ & $(-7.166)$ & $(-6.577)$ & $(-8.384)$ & $(-10.488)$ & $(-10.424)$ \\
\hline \multirow{2}{*}{$\Delta \mathrm{HK}_{t-4}$} & $0.1586 *$ & 0.1373* & $0.2138 *$ & $0.2228^{*}$ & 0.1163* & $0.1285 *$ \\
\hline & $(2.354)$ & $(2.226)$ & (3.567) & $(4.594)$ & $(2.382)$ & $(2.788)$ \\
\hline \multirow[t]{2}{*}{$\Delta \mathrm{HK}_{t-5}$} & $-0.4443^{*}$ & $-0.4363^{*}$ & $-0.3546 *$ & $-0.3270 *$ & $-0.3234 *$ & $-0.3033^{*}$ \\
\hline & $(-6.480)$ & $(-7.044)$ & $(-5.772)$ & $(-6.495)$ & $(-7.528)$ & $(-7.503)$ \\
\hline \multirow[t]{2}{*}{$\Delta \mathrm{J} \mathrm{P}_{t-1}$} & $0.6641 *$ & $0.5560 *$ & $0.4801 *$ & $0.4279 *$ & $0.5163 *$ & $0.5769 *$ \\
\hline & (3.357) & (3.032) & (2.692) & $(2.949)$ & $(4.079)$ & $(4.981)$ \\
\hline \multirow[t]{2}{*}{$\Delta J P_{t-2}$} & $0.7338^{*}$ & $0.8802 *$ & $0.5380 *$ & $0.7509 *$ & $0.8191 *$ & $0.8398 *$ \\
\hline & (3.884) & $(4.625)$ & (3.111) & $(4.763)$ & $(6.086)$ & $(6.653)$ \\
\hline \multirow[t]{2}{*}{$\Delta \mathrm{P}_{t-3}$} & $0.4803^{*}$ & $0.5983 *$ & 0.2703 & $0.3586 *$ & $0.4215^{*}$ & $0.4826^{*}$ \\
\hline & $(2.586)$ & (3.452) & $(1.607)$ & $(2.510)$ & $(3.451)$ & (4.155) \\
\hline \multirow[t]{2}{*}{$\Delta \mathrm{US}_{t-1}$} & $0.7477 *$ & 0.8786* & $0.6654 *$ & 0.8955* & $0.9116 *$ & $0.9042 *$ \\
\hline & $(2.274)$ & (2.939) & $(2.267)$ & $(3.584)$ & $(4.300)$ & $(4.671)$ \\
\hline \multirow[t]{2}{*}{$Z_{t-7}$} & $-0.2058^{*}$ & $-0.2435^{*}$ & $-0.1804 *$ & $-0.2100 *$ & $-0.2495 *$ & $-0.2621 *$ \\
\hline & $(-5.144)$ & $(-6.275)$ & $(-4.430)$ & $(-6.105)$ & $(-8.110)$ & $(-9.054)$ \\
\hline
\end{tabular}

$\Delta \mathrm{XJ} \mathrm{P}_{t-1} \quad 0.0462$

(1.957)

$\Delta X J P_{t-2} \quad 0.0614 *$

$(2.453)$

$\Delta \mathrm{XCN}_{t-3}-0.0650^{*}$

$(-2.902)$

$\Delta \operatorname{REER}_{t-1}$

$-0.1847 *$

$-0.0824 *$

$-0.0978 *$

$-0.0949 *$

$(-4.703)$

$(-6.344)$

$(-6.551)$

$(-2.285)$

$-0.2197 *$

$-0.1789 *$

$-0.1397 *$

$-0.1305$

$(-3.330)$

$(-3.112)$

$(-2.484)$

$\Delta \operatorname{REER}_{t-3}$

$(-1.537)$

$-0.1299$

$-0.1721 *$

$-0.1702 *$

$-0.0391 *$

$(-1.807)$

$(-2.779)$

$(-2.953)$

$\Delta \mathrm{RHSI}_{t-4}$

(-2.882)

$\Delta \mathrm{RNIK}_{t-1}$

0.0333

$0.0334 *$

0.0231

(1.995)

(2.382)

(1.883)

$\Delta \mathrm{RSP}_{t-4}$

-0.1225* -0.0957*

$-0.1045^{*}$

$(-4.723)$

$(-4.168)$

$(-4.835)$ 


\section{Table 5. Cont'd}

\begin{tabular}{|c|c|c|c|c|c|c|}
\hline Variables & Model 1 & Model 2 & Model 3 & Model 4 & Model 5 & Model 6 \\
\hline$\Delta \mathrm{HKRI}_{t-1}$ & & & $\begin{array}{c}-0.0012 * \\
(-2.573)\end{array}$ & $\begin{array}{c}-0.0016 * \\
(-4.114)\end{array}$ & $\begin{array}{c}-0.0015 * \\
(-4.373)\end{array}$ & $\begin{array}{c}-0.0012 * \\
(-3.597)\end{array}$ \\
\hline$\Delta \mathrm{HKRI}_{t-2}$ & & & $\begin{array}{c}-0.0020 * \\
(-3.274)\end{array}$ & $\begin{array}{c}-0.0022 * \\
(-4.301)\end{array}$ & $\begin{array}{c}-0.0017 * \\
(-3.685)\end{array}$ & $\begin{array}{c}-0.0021 * \\
(-4.718)\end{array}$ \\
\hline$\Delta \mathrm{HKRI}_{t-3}$ & & & $\begin{array}{c}-0.0016 * \\
(-2.712)\end{array}$ & $\begin{array}{c}-0.0014 * \\
(-2.874)\end{array}$ & $\begin{array}{c}-0.0012 * \\
(-2.855)\end{array}$ & $\begin{array}{c}-0.0013 * \\
(-3.247)\end{array}$ \\
\hline$\Delta \mathrm{PRI} \mathrm{I}_{t-1}$ & & & & $\begin{array}{c}-0.0011^{*} \\
(-2.123)\end{array}$ & $\begin{array}{c}-0.0016 * \\
(-3.341)\end{array}$ & $\begin{array}{c}-0.0012 * \\
(-2.771)\end{array}$ \\
\hline$\Delta \mathrm{DXJ} \mathrm{P}_{t-2}$ & & & & & $\begin{array}{c}0.0380 * \\
(3.531)\end{array}$ & $\begin{array}{c}0.0393^{*} \\
(3.929)\end{array}$ \\
\hline$\Delta R X U S_{t-2}$ & & & & & $\begin{array}{c}0.0339 * \\
(2.080)\end{array}$ & $\begin{array}{c}0.0383^{*} \\
(2.563)\end{array}$ \\
\hline$\Delta \operatorname{RERUS}_{t-1}$ & & & & & & $\begin{array}{c}-0.4221 * \\
(-2.962)\end{array}$ \\
\hline $\mathrm{Q}(4)$ & $\begin{array}{l}2.5483 \\
(0.636)\end{array}$ & $\begin{array}{l}2.1247 \\
(0.713)\end{array}$ & $\begin{array}{l}2.3727 \\
(0.668)\end{array}$ & $\begin{array}{l}3.5537 \\
(0.470)\end{array}$ & $\begin{array}{l}1.5780 \\
(0.813)\end{array}$ & $\begin{array}{l}3.2336 \\
(0.520)\end{array}$ \\
\hline $\mathrm{Q}(8)$ & $\begin{array}{l}6.6542 \\
(0.574)\end{array}$ & $\begin{array}{l}8.1603 \\
(0.418)\end{array}$ & $\begin{array}{l}3.9028 \\
(0.866)\end{array}$ & $\begin{array}{l}4.0424 \\
(0.853)\end{array}$ & $\begin{array}{l}2.5194 \\
(0.961)\end{array}$ & $\begin{array}{l}5.8945 \\
(0.659)\end{array}$ \\
\hline $\mathrm{Q}(12)$ & $\begin{array}{l}8.0372 \\
(0.782)\end{array}$ & $\begin{array}{l}9.2056 \\
(0.685)\end{array}$ & $\begin{array}{l}4.8952 \\
(0.961)\end{array}$ & $\begin{array}{l}5.9509 \\
(0.919)\end{array}$ & $\begin{array}{l}5.5180 \\
(0.938)\end{array}$ & $\begin{array}{l}7.7580 \\
(0.804)\end{array}$ \\
\hline J $B$ & $\begin{array}{l}0.3065 \\
(0.858)\end{array}$ & $\begin{array}{l}1.7400 \\
(0.419)\end{array}$ & $\begin{array}{l}0.5788 \\
(0.749)\end{array}$ & $\begin{array}{l}1.0910 \\
(0.580)\end{array}$ & $\begin{array}{l}0.7205 \\
(0.698)\end{array}$ & $\begin{array}{l}1.3452 \\
(0.510)\end{array}$ \\
\hline $\bar{R}^{2}$ & 0.7477 & 0.7965 & 0.8324 & 0.8926 & 0.9230 & 0.9324 \\
\hline $\operatorname{Min}\left(\hat{\varepsilon}_{t}\right)$ & $3.03 E-05$ & $1.6 \mathrm{E}-05$ & $5.4 \mathrm{E}-05$ & 0.000134 & $2.99 \mathrm{E}-05$ & $3.5 \mathrm{E}-05$ \\
\hline $\operatorname{Max}\left(\hat{\varepsilon}_{t}\right)$ & 0.02763 & 0.01985 & 0.01735 & 0.01259 & 0.01202 & 0.00978 \\
\hline
\end{tabular}

Note: The effective sample period is 85:4 - 99:2. The notation in the first column is defined as follows: HK = Hong Kong Per Capita GDP at 1990 prices, J P = J apan Per Capita GDP at 1990 prices, US = US Per Capita GDP at 1990 prices, Z = HK -1.833 J P +0.863 US is the error correction term, XJ P = Hong Kong Per Capita Exports to J apan at 1990 prices (deflated by Total Exports Unit Value Index), XCN = Hong Kong Per Capita Exports to China at 1990 prices (deflated by Total Exports Unit Value Index), REER = Hong Kong real effective exchange rate (Nov $83=100$ ), RHSI = Hang Seng index (adjusted by Composite Consumer Price index), RNIK = Nikkei 225 Index (adjusted by GDP deflator), RSP =S \& P 500 index (adjusted by GDP deflator), HKRI = Hong Kong 3-month real interest rate (construct from the ex-post Composite Consumer Price Index inflation rate), J PRI = J apan 3-month Real Interest Rate ((construct from the ex-post GDP deflator inflation rate), DX P $=$ Hong Kong Per Capita Domestic Exports to J apan at 1990 prices (deflated by the country-specific Unit Value Index), RXUS = Hong Kong Per Capita Re-exports to US at 1990 prices (deflated by Re-exports Unit Value Index), and RERUS = US dollar-based Hong Kong real exchange rate. Values in parentheses underneath the coefficient estimates are $t$-statistics. Significance at the $5 \%$ level is indicated by *. Q $(k)$ gives the Ljung-Box statistic constructed from the first $k$ autocorrelation coefficients. J B gives the J arque-Bera normality test statistic. The parentheses next to the $Q(k)$ and J B statistics contain their $p$-values. $\operatorname{Min}\left(\hat{\varepsilon}_{t}\right)$ and $\operatorname{Max}\left(\hat{\varepsilon}_{t}\right)$ are, respectively, the minimum and maximum of the absolute prediction errors. 
Figure 1. Per Capita Real GDP Growth Rates of Hong Kong, Japan, and the U.S.

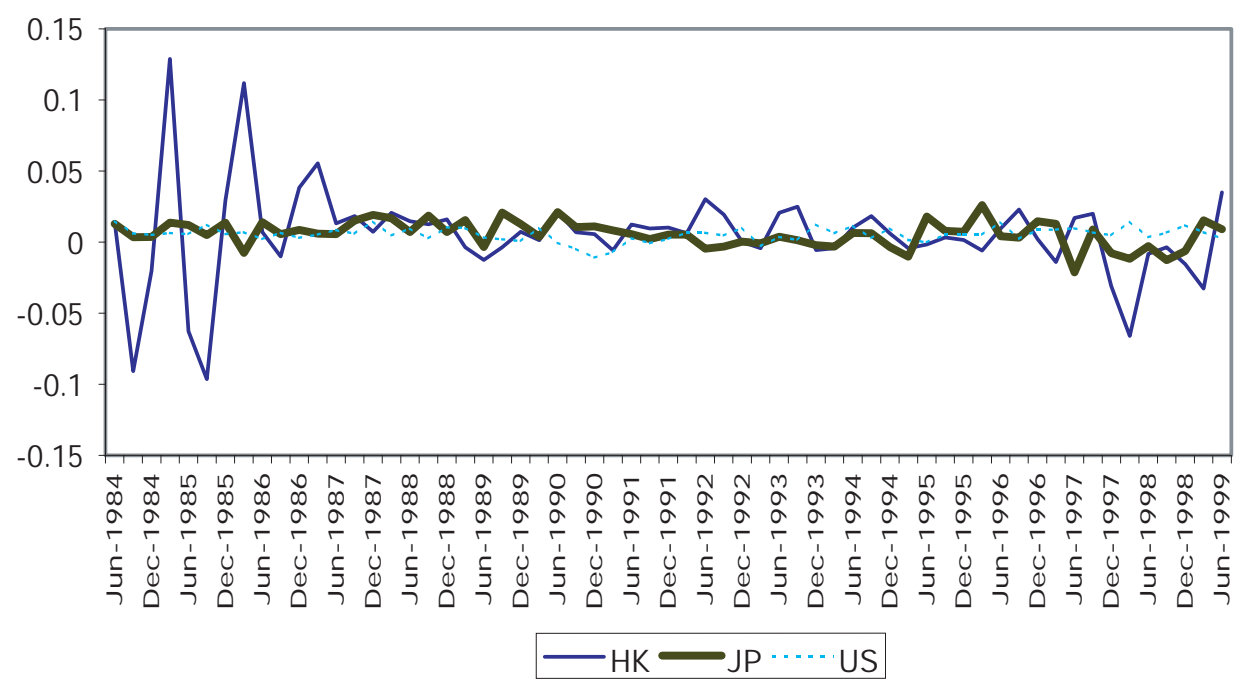

Figure 2. Generalized Impulse Response Functions: HK Output

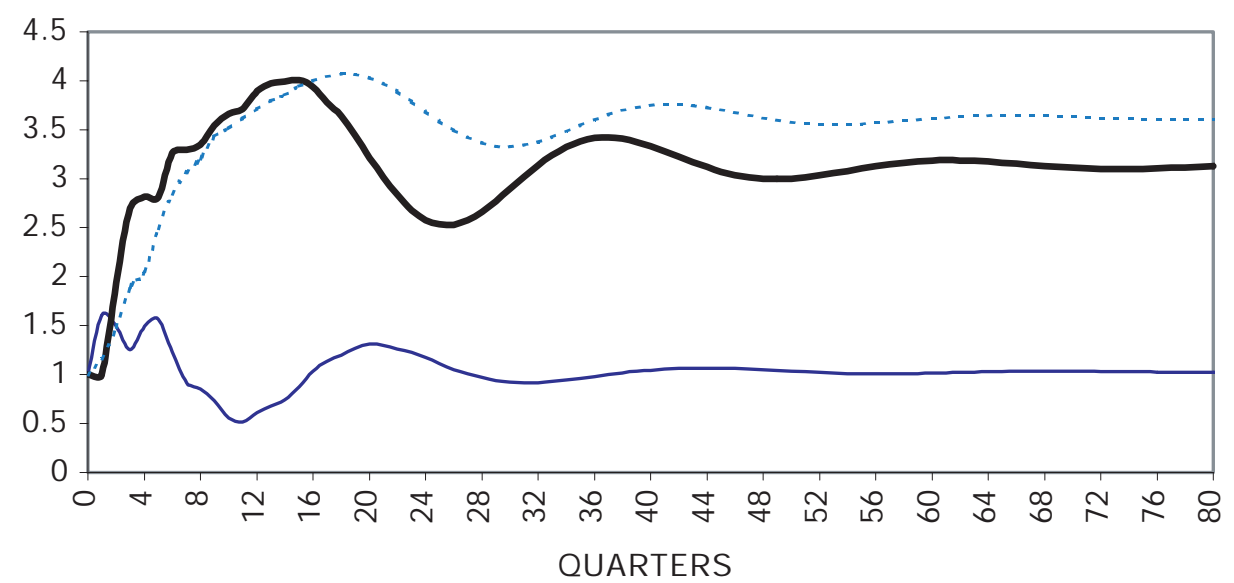

: the generalized impulse response of Hong Kong Output to a unit shock to Hong Kong Output. : the generalized impulse response of Hong Kong Output to a unit shock to J apan Output. : the generalized impulse response of Hong Kong Output to a unit shock to US Output. 
Figure 3. Generalized Forecast Error Variance Decomposition: HK Output

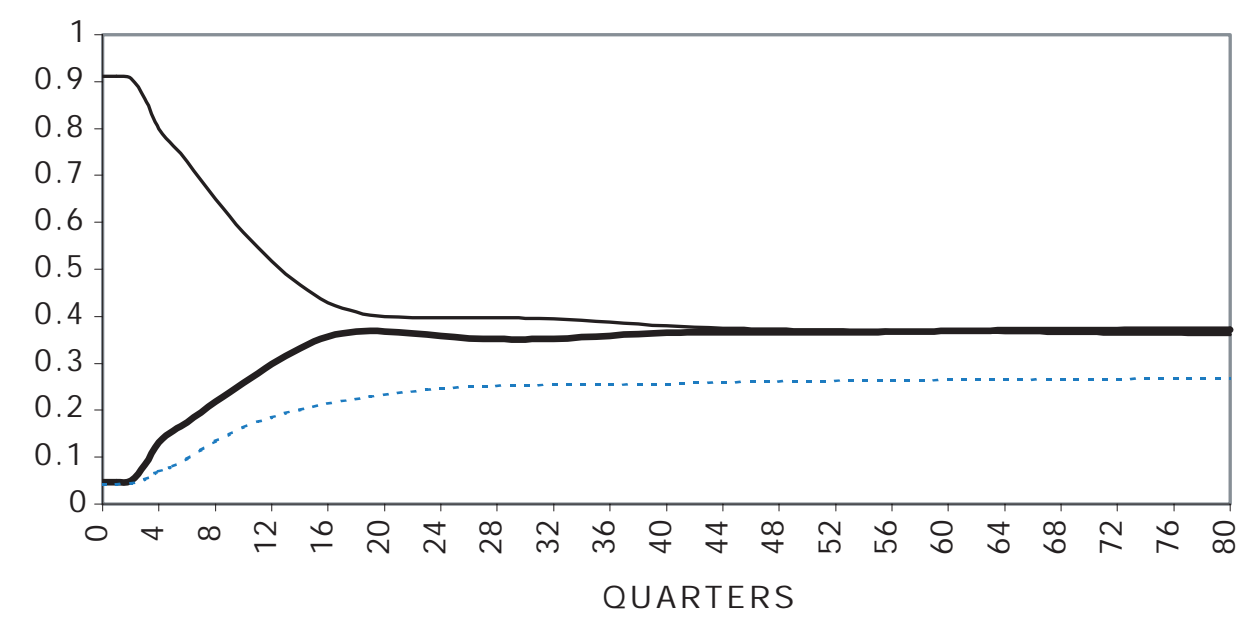

: the proportion of Hong Kong Output forecast error variance explained by Hong Kong shocks.

: the proportion of Hong Kong Output forecast error variance explained by J apan shocks. : the proportion of Hong Kong Output forecast error variance explained by US shocks. 
Figure 4. The Actual and Fitted Values from Models in Table 5

Model 1

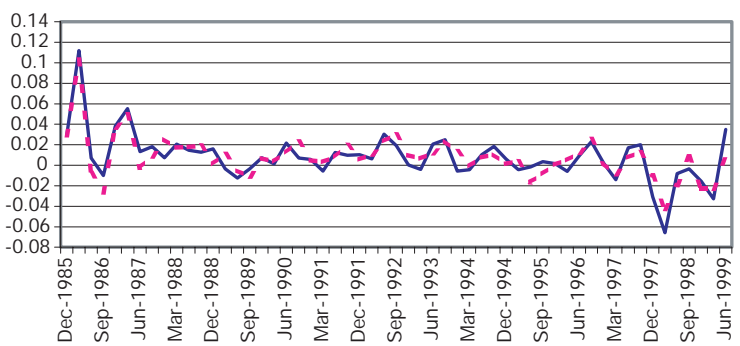

Model 3

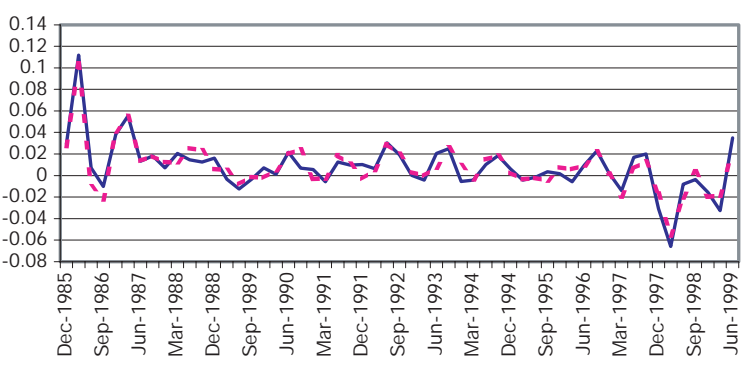

Model 5

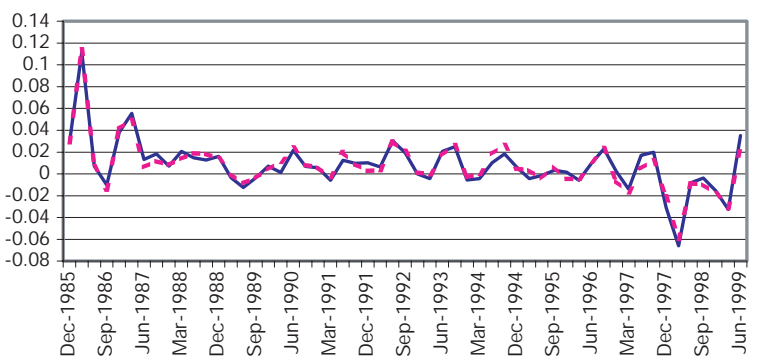

Model 2

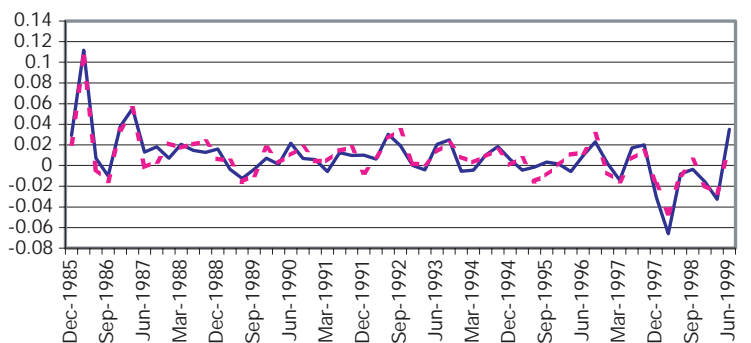

Model 4

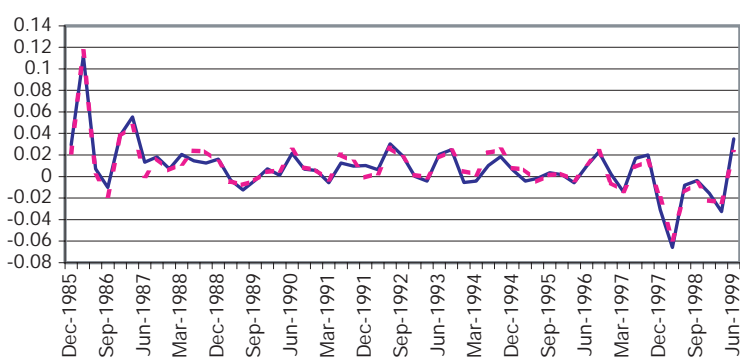

Model 6

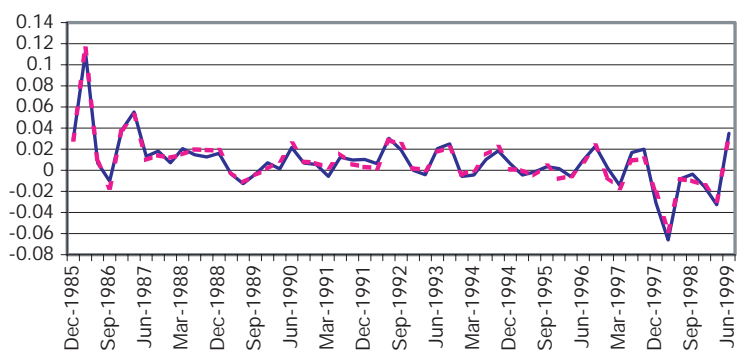




\section{Appendix}

\section{A. VEC Specifications for J apan and United States}

The VEC specifications for J apan and the U.S. are given in the following table:

1. J apan

Sample Period: 85Q4 - 99Q2

$\begin{aligned} \Delta J P_{t}= & 0.3635+0.1063 \Delta H K_{t-2}+0.2105 \Delta J P_{t-2}+0.3287 \Delta J P_{t-3}-0.3016 \Delta J P_{t-5}+0.0495 Z_{t-7} \\ & (2.076) \quad(2.234)\end{aligned}$

where $\mathrm{Z}_{t}=\mathrm{HK}_{t}-1.833 \mathrm{JP} \mathrm{P}_{t}+0.863 \mathrm{US}_{t}$

$\bar{R}^{2}=0.2234 \quad J \mathrm{~B}=3.9663(0.138)$

$\mathrm{Q}(4)=0.1290(0.998) \quad \mathrm{Q}(8)=3.3798(0.908) \quad \mathrm{Q}(12)=7.7156(0.807)$

2. United States

Sample Period: 85Q1 - 99Q2

$\begin{aligned} \Delta \mathrm{US}_{t}= & 0.0036-0.1242 \Delta \mathrm{P}_{t-3}+0.1610 \Delta \mathrm{US}_{t-1}+0.3007 \Delta \mathrm{US}_{t-2} \\ & (3.230)(-1.876)\end{aligned}$

$\bar{R}^{2}=0.1521 \quad J \mathrm{~B}=1.9717(0.373)$

$\mathrm{Q}(4)=0.8824(0.927) \quad \mathrm{Q}(8)=2.7846(0.947) \quad \mathrm{Q}(12)=9.8108(0.633)$

\section{B. Data Description}

The sample period covers 1984:I to 1999:II. Most of the data are retrieved from the CEIC database subscribed by the Hong Kong Monetary Authority. Some data are from the Datastream, the International Financial Statistics, and the Hong Kong Monetary Authority internal database. Note that only the variables that yield significant estimation results are included in the text.

1. per capita real GDP data

The population and real GDP data at 1990 prices are used to construct per capita real GDP. The U.S. and J apan quarterly population data are monthly averages. The Hong Kong quarterly population data are interpolated from semi-annual data. The U.S. and J apan real GDP data are seasonally adjusted at the source. The Hong Kong real GDP are seasonally adjusted using regression dummies. 
2. per capita real exports

The real export series are obtained from the nominal series and the Total Exports Unit Value Index. The de-seasonalized data (using regression dummies) are used to derive the per capita data.

3. real stock indexes

The quarterly stock indexes are averages of daily closings. The Hang Seng Index is adjusted by the Composite Consumer Price Index. The Nikkei 225 index and the Standard \& Poors 500 Index are adjusted by their respective GDP deflators.

4. real interest rates

The nominal interest rates are the three-month Euro yen, Euro dollar, and HIBOR rates. Ex-post GDP deflator inflation rates are used to construct the J apan and U.S. real interest rates. The Hong Kong real interest is derived from ex-post inflation rates based on the Composite Consumer Price Index.

5. per capita real domestic exports

The nominal domestic export data and the country-specific Domestic Exports Unit Value Indexes are used to compute the real domestic exports series. The data are seasonally adjusted using the regression dummy approach before converting to per capita series.

6. per capita real re-exports

The nominal re-export data and the Re-Exports Unit Value Index are used to compute the real reexports series. The data are seasonally adjusted using the regression dummy approach before converting to per capita series.

\section{7. real exchange rates}

The real effective exchange rate $(83: 11=100)$ is provided by the Hong Kong Monetary Authority. The U.S. dollar-based and J apanese yen-based Hong Kong dollar real exchange rates are constructed from the corresponding consumer price indexes and exchange rates.

The first log differences of the per capita real GDP series are plotted as Figure 1 in the manuscript. The graphs of the first log differences of the other series are given as follows: 
B1: Per Capita Real Exports (First Logarithmic Differences)

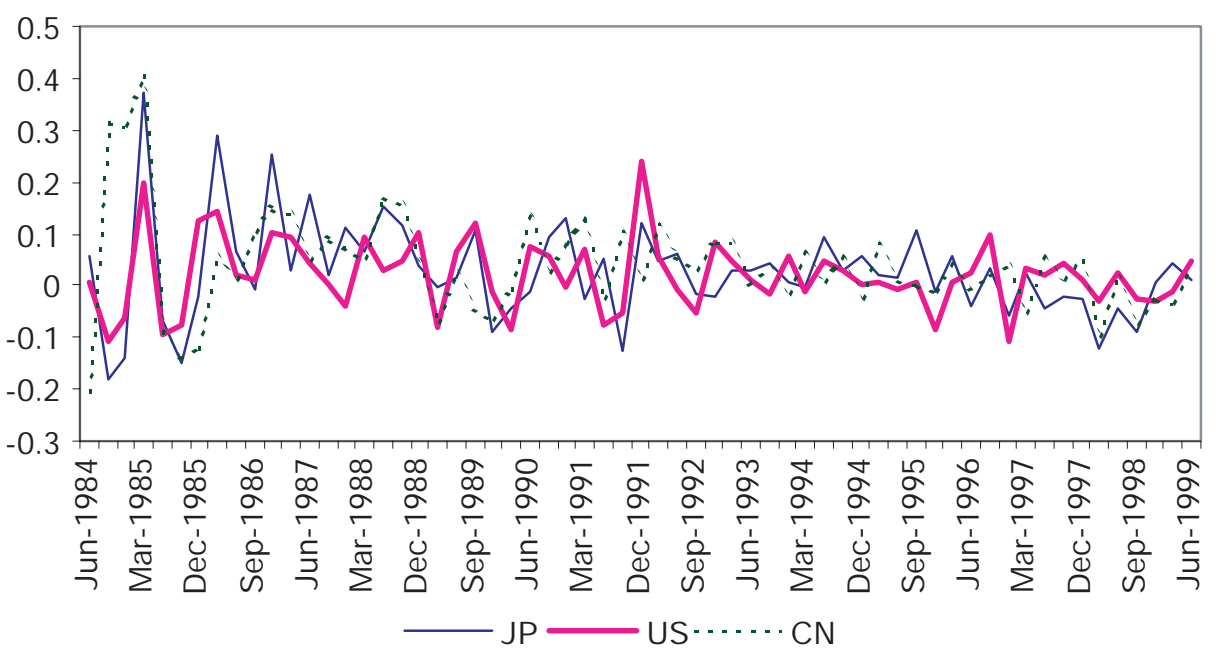

B2: Real Stock Indexes (First Logarithmic Differences)

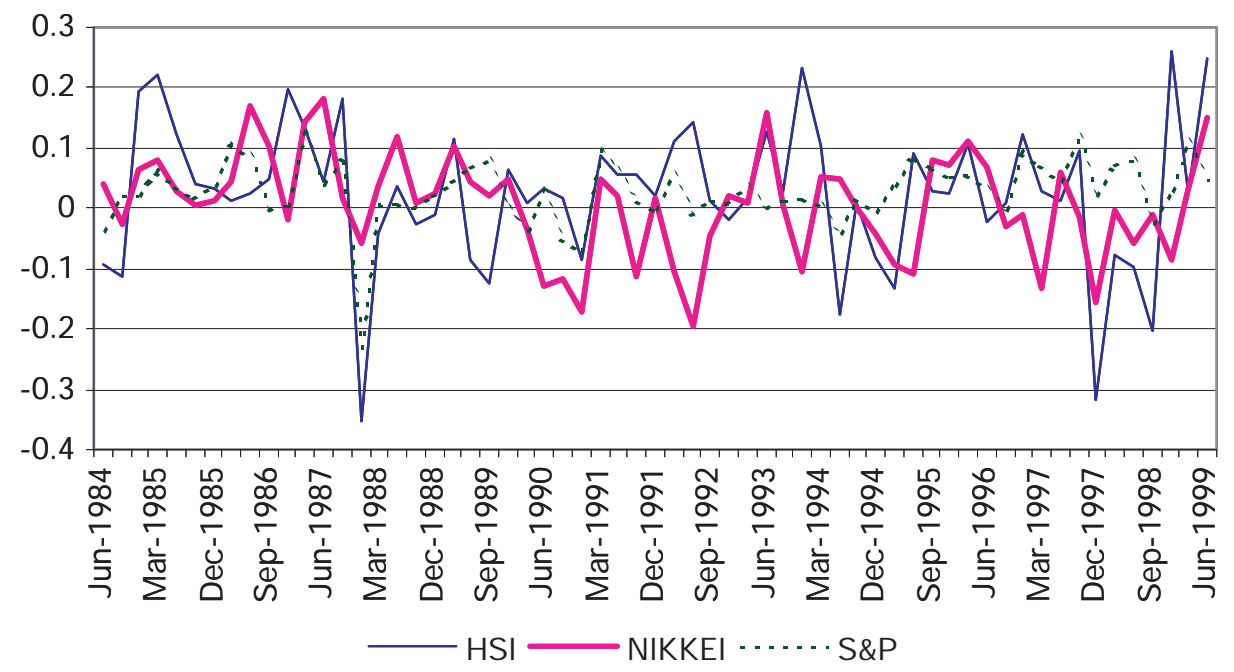


B3: Real Interest Rates (First Differences)

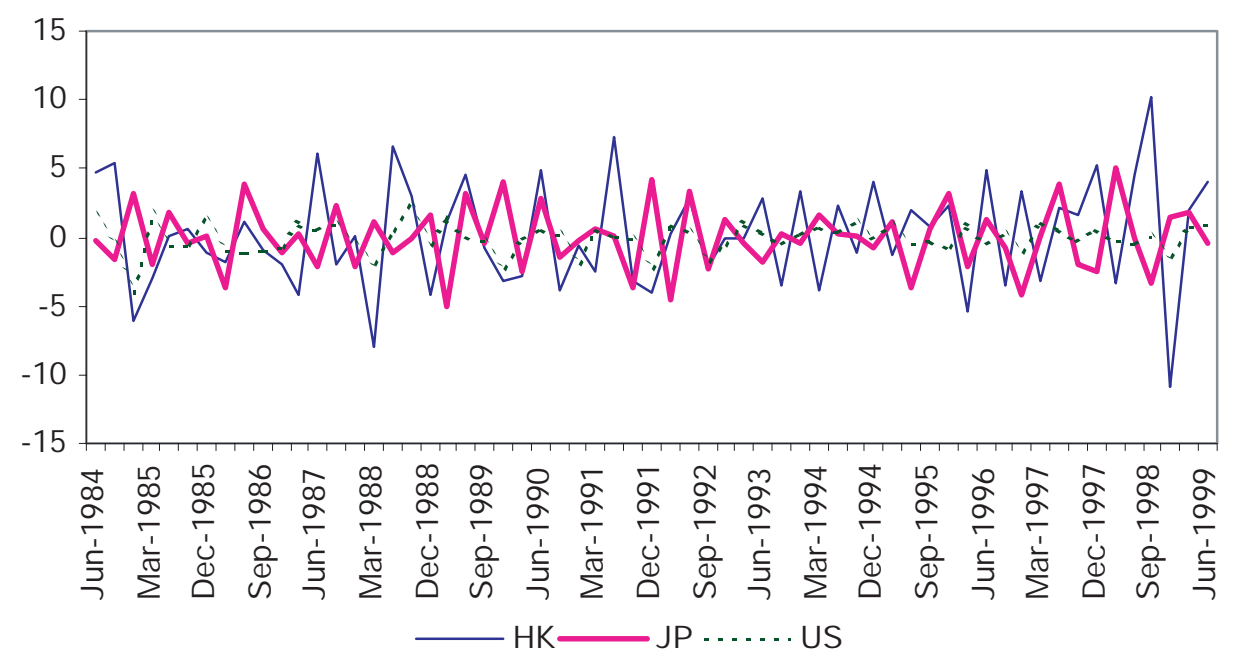

B4: Per Capita Real Domestic Exports (First Logarithmic Differences)

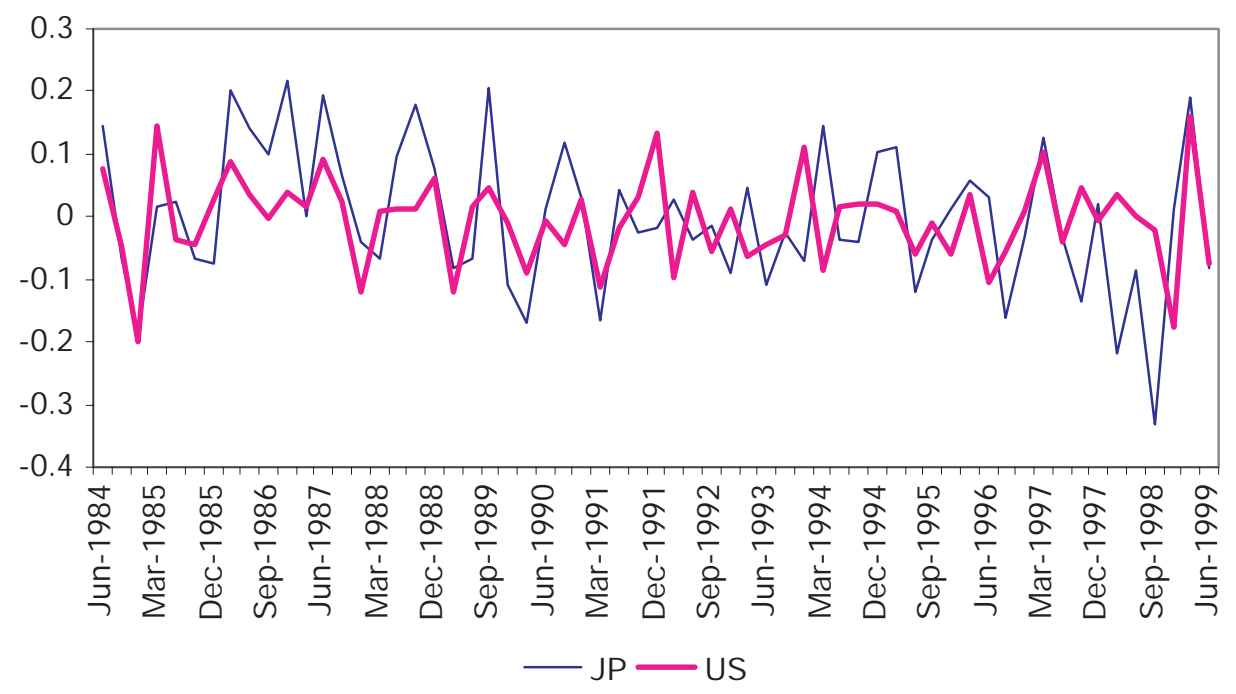


B5: Per Capita Real Re-Exports (First Logarithmic Differences)

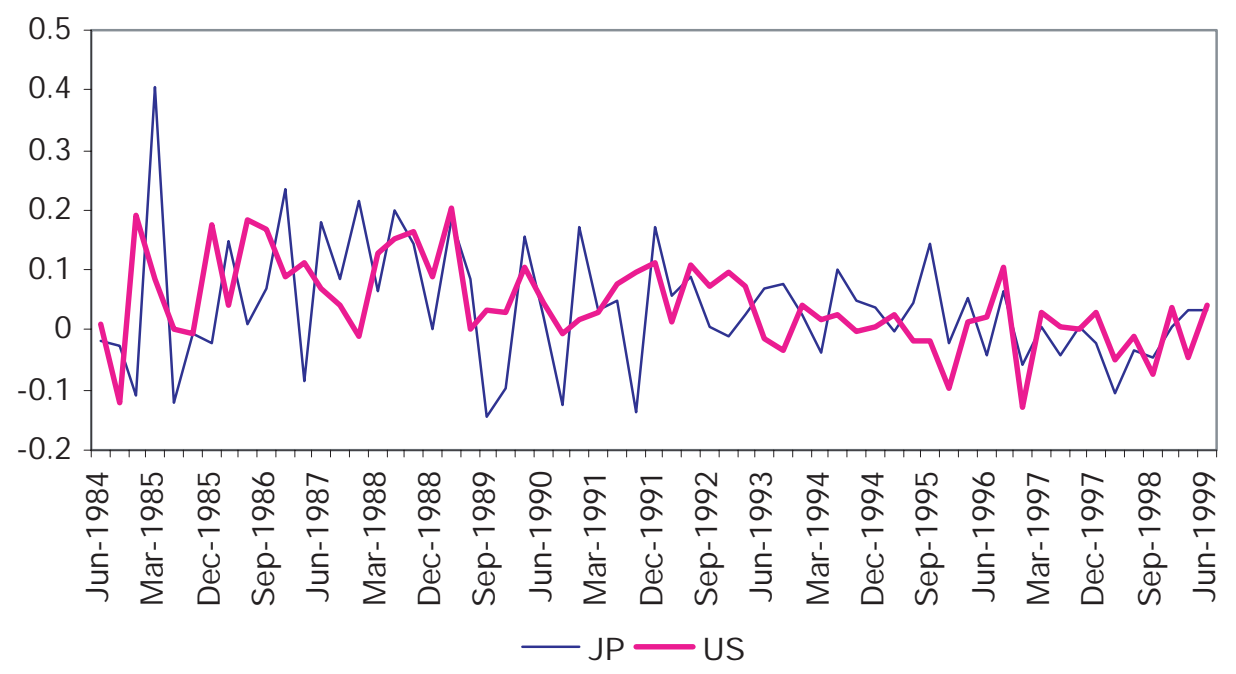

B6: Real Exchange Rates (First Logarithmic Differences)

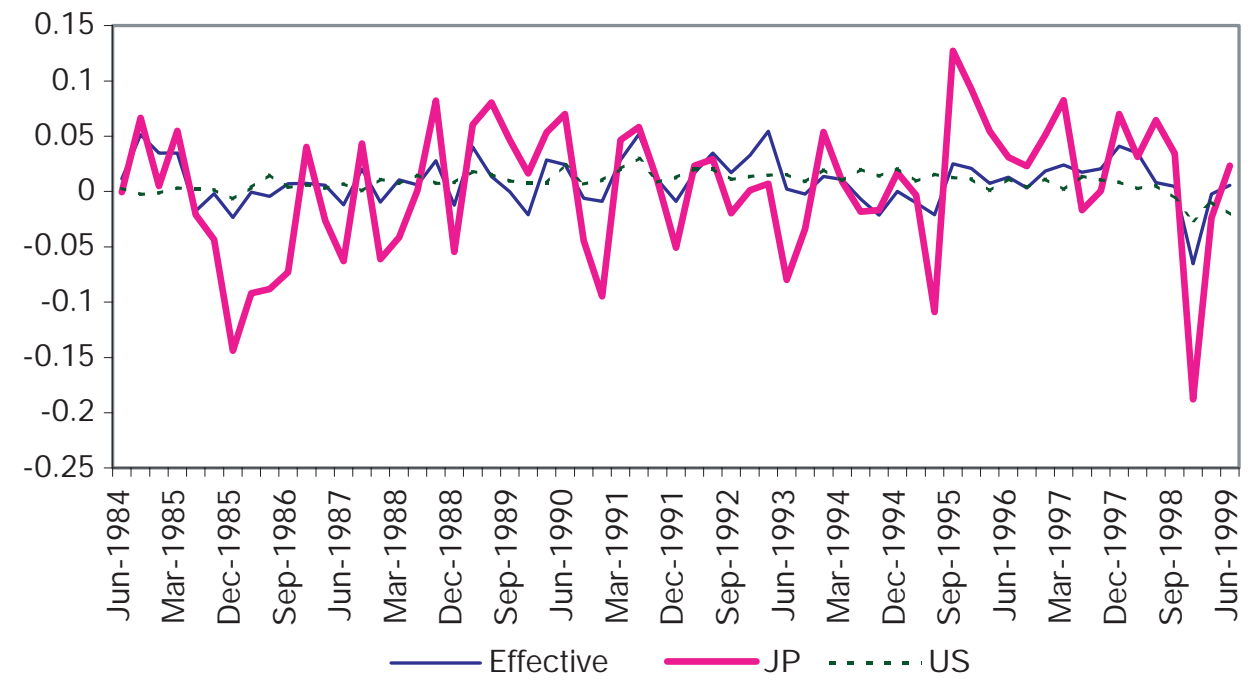

